UDC 314.44

DOI: 10.21668/health.risk/2021.2.14.eng

Research article

\title{
RESTRICTED ACTIVITY AND NEGATIVE SELF-ASSESSMENT OF HEALTH AS RISK INDICATORS FOR LATENT DISABILITY ANALYSIS PERFORMED ON POPULATION GROUPS DIFFERENT AS PER SEX AND AGE
}

\author{
L.N. Natsun \\ Vologda Research Center of the Russian Academy of Sciences, 56a Gor'kogo Str., Vologda, 160014, \\ Russian Federation
}

\begin{abstract}
A necessity to detect and assess probable latent disability makes the present research vital; it can be done using available parameters that characterize population health.

Our research object was adult population living in the Russian Federation.

Our research goal was to reveal a relation between self-assessment of health and health-related restrictions among respondents form different sex and age groups in order to determine latent disability among overall RF population.

Previously Russian researchers revealed certain relations between disability and low self-assessment of one's health. However, there was no profound study on an issue related to using such criteria as «negative self-assessment of health» and «restricted activities» used to reveal latent disability. This aspect has not been examined in great detail in domestic research and it makes the present work truly vital. We took data collected via the Russian sociologic study performed within the European sociological study (ESS) in 2018-2019 as well as data from sampling studies on population in the RF performed by the Federal Statistics Service in 2018 and 2019. To analyze a relation between self-assessment of health and existing restricted activity, we calculated Kramer's coefficients for different sex and age groups of respondents who took part in the Russian sociologic study.

Calculated Kramer's coefficient values indicate there is an average relation between such parameters as «selfassessment of health» and «existing restricted activity». We established that $7 \%$ of respondents who were not disabled still had health characteristics implying there was a disability risk. It was shown that use of such criteria as «self-assessment of health» and «existing restricted activities» allowed more authentic assessment of latent disability among males aged 50-59 and women aged 20-29, 30-39, and 40-49. In future we plan to obtain more accurate results using data from other representative sociologic studies on population including regional ones.

Key words: population health, disability, restricted activity, self-assessment of health, sociologic study, measuring disability levels.
\end{abstract}

The WHO experts believe that disability among population is inseparably linked to demographic ageing and a growth in chronic diseases burden. In 2015 there were more than 1 billion disabled people all over the world and the number was expected to grow [1]. In the Russian Federation there were 11.875 million disabled people registered on January 1, 2020 and it was approximately $8 \%$ of the total country population. Researchers often mention that a system applied for statistic register of disability is rather imperfect since it contains data only on those people who have applied for being registered as disabled [2]. This un- derestimation creates a distorted picture of the current situation in public health since it doesn't take into account hidden risks of demographic losses caused by latent disability; it also results in incorrect predictions for a scope of public expenditure on healthcare and social support provided for population. Certain positive experience was gained in some countries in applying a specific questionnaire developed by the WHO and the World Bank for revealing actual numbers of disabled people [3]; unfortunately, this experience is still neglected in Russia. The outlined issues are rarely given any attention in domestic scien-

(C) Natsun L.N., 2021

Leila N. Natsun - Research Fellow (e-mail: leyla.natsun@yandex.ru; tel.: +7 (8172) 59-78-10 (ext. 318); ORCID: https://orcid.org/0000-0002-9829-8866). 
tific literature. A.O. Makarentseva et al. [4] discuss a methodical approach to revealing "latent" disability using data obtained via representative sociological studies. This approach is based on disability criteria determined as per "procedures by the Washington Group on Disability Statistics"; however, the authors point out that they obtained rather ambiguous results for women from older age groups. Samplings that are surveyed in sociological studies (including those aimed at studying disabled people's opinions), as a rule, include negligibly small number of people who are officially registered as "disabled". At the same time, disability means that a person has to face some restrictions in his or her life activities; according to data obtained via sociological studies, disability is more often accompanied with low self-assessment of health [5]. Indirect signs of disability (restricted life activity) are mentioned by notably greater number of respondents and it allows considering them as people who have failed to exercise their rights to be registered as "disabled".

In the present work we plan to examine how those people who think their life activities are restricted assess their health. We assume that restricted life activity combined with negative self-assessment of health leads to greater probability that a person is already registered as disabled or plans to do it in the nearest future. On the other hand, a significant share of people who are not registered as disabled but still state that their life activities are restricted and their health is rather poor may indicate that such people face substantial difficulties in registering as disabled, or they do not wish to do it since disabled people are seen as a discriminated group.

While accomplishing our research, we took into account methodological limitations of applied instruments. Thus, there are certain difficulties in achieving uniform interpretations of reasons for self-assessment of health. For example, not every questionnaire contains not only a direct question on how a person assesses his or her health but also a clarifying question on reasons that make a respondent assess his or her health as good or poor. These reasons can be overall health, chronic diseases, injuries, psychological state, etc. On the other hand, self-assessment of health can be influenced indirectly by social and economic factors $[6,7]$. M.A. Kaneva and V.M. Baidin [8] highlight that it is important to take heterogeneity into account when self-assessment of health is analyzed. Foreign researchers took data obtained via a longitude survey and showed that social capital exerted significant impacts on self-assessment of health [9]. Higher self-assessment of health is typical for people who tend to have higher social trust, are able to enter intense informal interactions, have variable friendly relations and are involved in activities performed by social organizations [10]. Similar conclusions were made by researchers who examined data obtained via sociological questionings performed in Russia [11]. Several research works published abroad concentrated on a complicated relation between self-assessment of health, life quality, existing restrictions in life activities and objective parameters of people's health and lifestyle. Thus, a lower self-assessment of health may result from loss of a job and people with objectively poorer health run greater risk of such an event [12]. At the same time, objective characteristics that indicate poor health may exert smaller influence on respondents' assessment of their life quality than existing restricted life activities. Thus, Whitley et al. showed in the research [13] that absence of any restrictions in life activities was seen as a significant condition of proper ageing by elderly people whereas absence of a chronic disease was not considered to have the same significance. Self-assessment of health by employed population is significantly influenced by microclimate and other conditions at a workplace (noise and air contamination) [14]. A lot of foreign and domestic authors have mentioned a relation between subjective assessments of health made by respondents and their social and demographic characteristics [15-17]. Gender-related peculiarities typical for self-assessment of health have also been studied in detail as well as gender-related specificity of factors that influenced distribu- 
tions of these self-assessments ${ }^{1}$ [18]. Given all the above mentioned, we should note that results obtained in our present research require more detailed validation in future research.

Data and methods. We took adult population in the Russian Federation as our research object. Our research subject was a correlation between self-assessments of health and restricted life activities as per different age and sex groups in adult population.

Our research goal was to reveal correlations between self-assessments of health and restricted life activities among respondents from different age and sex groups in order to determine latent disability among population in Russia. To achieve this goal, we had to solve the following tasks:

1) to analyze prevalence of restricted life activities among respondents;

2) to examine a correlation between such variables as "self-assessment of health" and "restricted life activities" in different age and sex groups;

3) to analyze a correlation between a structure of a population group determined as per such parameters as negative self-assessment of health and restricted life activities and a population group that includes "disabled people".

Information basis of the research was made up of data obtained via Russian Social Survey accomplished as per a program developed by European Social Survey (ESS). The questioning was performed by CESSI (Institute for Comparative Social Research) in November 2018 - February 2019 via personal interviews conducted at respondents' homes on a random probability sampling of the country population with respondents being not younger than 15 . Overall, 2,416 people were questioned. The research methodology is described in detail in the project technical documentation ${ }^{2}$.

Apart from data obtained via the European Social Survey, we also took data obtained via the sampling observation over population health (VN SZN-2019) and sampling observation over behavioral factors that influence population health (VN PFZN-2018) performed by Rosstat in 2019 and 2018 accordingly. A unit in observation was a household (household members) with only one member in each household being included into the observation (respondents were 15 years or older). 60 thousand households took part in the sampling observation SZN-2019; 15 thousand households, in VN PFZN-2018.

Respondents' belonging to this or that sex and age group can exert significant influence on examined health parameters such as selfassessment, existing restrictions in life activities, and disability. Respondents included into the sampling examined within Russian Social Survey (RSS) were distributed as per sex and 10-year age groups (plus groups made up of people aged 15-19 and people aged 70 and older). Number of respondents in groups aged 15-19 and 70 and older turned out to be substantially lower in comparison with other age group in the total RSS sampling (68 and 72 people accordingly). These groups were not examined in the present research and we didn't calculate correlations between self-assessment of health and existing restricted life activities for them. Calculation of Cramer's V-coefficient was applied as a procedure that allowed determining whether there was a significant correlation between such variables as "self-assessment of health" and "existing restrictions of life activities" 3 . The procedure was selected due to an essence of examined variables (they are nominal values).

The next step was to check any coincidence in structure of groups made up of respondents with disability and respondents who assessed their health as poor and had certain restrictions of their life activities. To do that we created an additional variable that was called "negative self-assessment of health" and

\footnotetext{
${ }^{1}$ Nazarova I.B. Employed population's health: a monograph. Moscow, MAKS Press, 2007, 526 p.

${ }^{2}$ Russian Social Survey as per a program developed by European Social Survey. European Social Survey. Available at: www.ess-ru.ru (April 20, 2020).

${ }^{3}$ This coefficient is applied for nominal values and its values vary from 0 to 1 . The closer a value is to 1 the higher is a probability that there is a statistical correlation between examined parameters.
} 
existing restrictions in life activities" in our research database. Then we created a combination table on "disability" and "negative selfassessment of health" and existing restrictions in life activities" variables.

Results and discussion. Prevalence of restricted life activities among adult population in Russia. According to data provided by Rosstat $^{4}$ a number of disabled people aged 18 and older amounted to 11.28 million people on January 1, 2018; 4.8 million were men and 6.48 million were women. Overall number of disabled per 1,000 people amounted to 81.4 (or $8 \%$ of the overall country population). These data cover only people who are officially registered as disabled. In order to obtain more precise number of disabled people, we suggest examining data obtained via representative sampling observation over population health in Russia.

A questioning used in the sampling observation over population health (VN SZN-2019) contained a block of questions called "health" where respondents were offered, among other things, to give self-assessment of their health; another block was called "Life activities of an adult person" and included questions aimed at detecting possible restricted life activities. According to data obtained via this research approximately $8 \%$ of the adult population in Russia stated that their health was "poor" and it was quite similar to the registered overall number of disabled people. At the same time, according to data obtained via the sampling observation over behavioral factors that influence population health (PFSZ-2018), a share of respondents who thought their health to be poor or very poor was substantially higher as it amounted to $13 \%$ (Table 1). However, this substantial change in distribution of health assessments could be caused by different reasons for giving an answer to this question ${ }^{5}$.

Overall, these distributions of health assessment indicate that from 8 to $13 \%$ of the adult population in the country have more or less serious health problems that prevent them from assessing their health as satisfactory or good.

Let us analyze data obtained via Russian Social Survey performed as per ESS program (RSS) and data obtained due to the $9^{\text {th }}$ wave in European Social Survey (ESS). In both surveys, respondents were asked to assess their health (answer variants were comparable). And it was in Russia where a share of respondents who assessed their health as "poor" and "very poor" (11\% altogether) was high together with a small share of people who assessed their health as "good" (42\%). The highest shares of positive answers were given in Switzerland $(84 \%)$ and Ireland $(81 \%)$ (Table 2).

Table 1

Self-assessments of health by Russian population as per data obtained via two sampling observations

\begin{tabular}{|l|c|c|}
\hline \multirow{2}{*}{\multicolumn{1}{|c|}{ Self-assessment of health }} & \multicolumn{2}{c|}{ Sampling observation data } \\
\cline { 2 - 3 } & VN SZN-2019 & VN PFSZ-2018 \\
\hline Good and very good & 56.3 & 39.6 \\
\hline Satisfactory & 35.7 & 47.1 \\
\hline Poor and very poor & 7.8 & 13.1 \\
\hline
\end{tabular}

Source: data obtained via sampling observations over population health and behavioral factors that influence population health ${ }^{3}$.

\footnotetext{
${ }^{4}$ The situation with disabled people. The Federal State Statistic Service. Available at: https://www.gks.ru/folder/13964 (April 20, 2020).

${ }^{5}$ A clarifying question on reasons that made a respondent give this or that assessment of his or her health was included into the VN PFSZ-2018; however, a distribution of answers to it was not given in the ultimate observation results. Data obtained via VN SZN-2019 could allow assessing prevalence of restricted life activities among population but answers to relevant questions were not published.
} 
Table 2

Distribution of health assessments in European countries (\% of the overall population)

\begin{tabular}{|l|c|c|c|c|c|c|c|c|}
\hline Self-assessment of health & Ireland & Cyprus & Switzerland & Norway & Hungary & Bulgaria & Estonia & Russia \\
\hline Very good & 40 & 41 & 37 & 33 & 17 & 16 & 11 & 7 \\
\hline Good & 41 & 34 & 47 & 44 & 45 & 42 & 41 & 35 \\
\hline Satisfactory & 15 & 20 & 13 & 18 & 28 & 31 & 37 & 46 \\
\hline Poor & 3 & 4 & 2 & 4 & 7 & 9 & 9 & 10 \\
\hline Very poor & 1 & 1 & 0 & 1 & 2 & 3 & 2 & 1 \\
\hline
\end{tabular}

Source: data obtained via Russian Social Survey as per ESS program and data obtained within the $9^{\text {th }}$ wave of European Social Survey (ESS).

Respondents' distribution as per restricted life activities in European countries

( $\%$ of the total number of respondents)

\begin{tabular}{|l|c|c|c|c|c|c|c|c|}
\hline $\begin{array}{c}\text { Self-assessment } \\
\text { of health }\end{array}$ & Ireland & Cyprus & Switzerland & Norway & Hungary & Bulgaria & Estonia & Russia \\
\hline Grave restrictions & 5 & 4 & 4 & 6 & 4 & 4 & 8 & 6 \\
\hline Certain restrictions & 14 & 17 & 16 & 22 & 17 & 14 & 23 & 29 \\
\hline No restrictions & 81 & 79 & 80 & 73 & 78 & 83 & 68 & 64 \\
\hline
\end{tabular}

Source: data obtained via Russian Social Survey as per ESS program and data obtained within the $9^{\text {th }}$ wave of European Social Survey (ESS).

Table 4

Distribution of respondents' health assessment depending on restricted life activities ( $\%$ of the overall number of respondents)

\begin{tabular}{|l|c|c|c|c|c|c|}
\hline $\begin{array}{c}\text { Restricted life activities / } \\
\text { health self-assessment }\end{array}$ & Very good & Good & Satisfactory & Poor & Very poor & All respondents \\
\hline Grave restrictions & 0 & 10 & 20 & $\mathbf{4 9 . 3}$ & $\mathbf{2 0 . 7}$ & 6.2 \\
\hline Certain restrictions & 0.1 & 9.3 & 67.3 & $\mathbf{2 2 . 2}$ & 1.1 & 30.9 \\
\hline No restrictions & 10.1 & 48.2 & 39.7 & 1.9 & 0.0 & 62.8 \\
\hline All respondents & 6.4 & 33.8 & 47.0 & 11.1 & 1.6 & 100 \\
\hline
\end{tabular}

Source: data obtained via Russian Social Survey as per ESS program; results obtained for 2,404 observations.

In both surveys, respondents were also asked whether they had any restrictions in life due to physical handicaps or disability. Russia also turned out to be among the most unfavorable countries as per a share of people who didn't have any restrictions in life. At the same time, a share of people who have grave restrictions in our country is close to values obtained for other European countries. Basic differences were detected regarding those respondents who, in their own opinion, had certain restrictions in life. An overall picture of respondents' distributions as per existing restrictions of life activities is the most favorable in Bulgaria, Ireland, and Switzerland (Table 3).

Self-assessment of health and restricted life activities (analysis of correlation based on data obtained via social surveys). Data obtained via European and Russian Social Surveys allow comparing respondents' selfassessments of health and existing restrictions of their life activities. Table 4 contains data on distribution of health assessments among respondents from three groups: without any restrictions, with certain restrictions, and with grave restrictions. We can see a correlation between the examined parameters. Thus, only $10 \%$ respondents with grave restrictions assessed their health as good and the biggest share in this group stated it was poor (49\%) or very poor $(21 \%)$. Positive assessments were much more frequent among respondents without any restrictions $(58 \%)$ and low assessments were quite rare $(2 \%)$ (Table 4$)$. The 
questionnaire used in 2018 didn't contain a question on reasons that made respondents give this or that assessment of their health. At the same time, this distribution given in Table 4 allows assuming that existing restrictions in life activities are among such reasons.

At the same time, as it was mentioned above, the same factor can be significant regarding its influence on respondents' selfassessments of health in some demographic groups and insignificant in others. To clarify this correlation between self-assessment of health and existing restrictions of life activities, let us examine the data as per different social and demographic groups. To do that, we should divide the sampling into certain groups as per sex and 10-year age groups.

There were substantial variations in prevalence of restricted life activities in specific age and sex groups of respondents. The greatest share of people with any restrictions was detected among respondents aged 60-69; the lowest share, among respondents aged 20-29 (Figure).

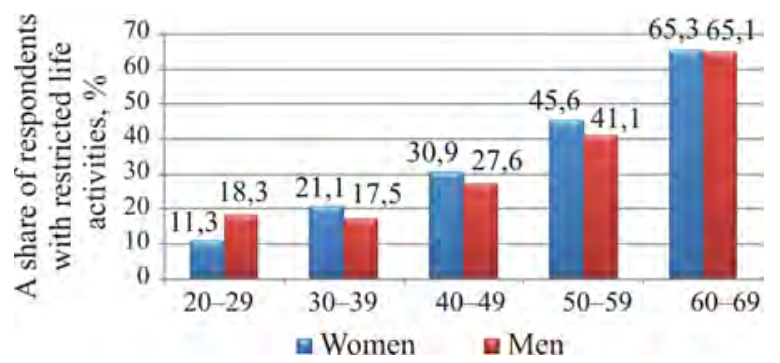

Figure. Prevalence of any restricted life activities among respondents from different age and sex groups ( $\%$ of a number of respondents in a relevant group)

Source: calculated as per data obtained via Russian Social Survey as per ESS program

We calculated Cramer's V-coefficient values to reveal correlations between respondents' self-assessments of health and existing restricted life activities (Table 5).

The obtained data indicate that there is an average correlation between such criteria as "self-assessment of health" and "existing re- strictions in life activities". And coefficient values are a bit lower for men aged 30-39 and women aged 40-49 than for other groups. The maximum Cramer's V value for women was obtained for people aged $60-69(0.455)$; the maximum value for men $(0.570)$ was obtained for people aged 20-29. Overall, Cramer's V values calculated for men (excluding group aged 30-39) were higher than values calculated for women. It allows us to assume that men took into account any life restrictions to a greater extent than women when assessing their health. At the same time, as we will show a bit later, women who don't have any restrictions in their life activities tend to assess their health lower than men and it explains the obtained coefficient values. It was especially apparent for women aged 40-49 who didn't have any restrictions in their life activities (Table 6).

Restricted life activities make people believe their health is poor thus resulting in low self-assessments of it. Thus, a longitude survey that was performed in Great Britain revealed that elderly people with poorer hearing and eyesight tended to assess their health lower than their counterparts without such disorders [19]. Some surveys performed in Russia showed that there was a correlation between disability and self-assessment of health and these assessments tended to be negative more frequently among disabled people [5]. In our research more frequent negative self-assessments of health were detected among respondents who had restricted life activities, regardless of their belonging to a specific sex and age group, against respondents without any restrictions ${ }^{6}$. It allows assuming that restricted life activities make for lower self-assessment of health. A share of negative health assessments grew among men with restricted life activities in each next age group. The only exclusion was a group made up of men aged 30-39. As for women who had restricted life activities, the highest share of negative health assessments was detected among those aged 60-69 (34\%). But when it

\footnotetext{
${ }^{6}$ As we have already mentioned, a number of respondents aged 15-19 and 70 and older was substantially lower than in other age groups; therefore Table 6 doesn't contain any data on these age groups.
} 
Table 5

Cramer's V-coefficient values for "self-assessment of health" and "existing restrictions in life activities" in different sex and age groups of respondents

\begin{tabular}{|c|c|c|c|c|c|c|}
\hline \multirow{2}{*}{ Age groups } & \multicolumn{3}{|c|}{ Men } & \multicolumn{3}{c|}{ Women } \\
\cline { 2 - 7 } & Cramer's V & $\begin{array}{c}\text { Feasible } \\
\text { observations, } \\
\text { number }\end{array}$ & Significance & Cramer's V & $\begin{array}{c}\text { Feasible } \\
\text { observations, } \\
\text { number }\end{array}$ & Significance \\
\hline $20-29$ & $\mathbf{0 . 5 2 9}$ & 225 & 0.000 & 0.390 & 189 & 0.000 \\
\hline $30-39$ & 0.376 & 275 & 0.000 & 0.438 & 205 & 0.000 \\
\hline $40-49$ & 0.501 & 194 & 0.000 & 0.366 & 186 & 0.000 \\
\hline $50-59$ & 0.482 & 143 & 0.000 & 0.452 & 252 & 0.000 \\
\hline $60-69$ & 0.476 & 115 & 0.000 & $\mathbf{0 . 4 5 5}$ & 248 & 0.000 \\
\hline
\end{tabular}

Source: calculated as per data obtained via Russian Social Survey using IBM SPSS Statistic software (ver.22.0). Data were preliminarily weighted in order to provide representativeness as per created age and sex groups.

Table 6

A share of respondents who assessed their health as "very poor" and "poor" in different sex and age groups (in \% of the total number of respondents)

\begin{tabular}{|l|c|c|c|c|c|}
\hline \multicolumn{1}{|c|}{ Sex and age groups } & $20-29$ & $30-39$ & $40-49$ & $50-59$ & $60-69$ \\
\hline Women \\
\hline Have restrictions of life activities & 18.2 & 20.9 & 22.8 & 21.1 & 34 \\
\hline No restrictions & 1.8 & 1.9 & 4.7 & 0.7 & 1.2 \\
\hline & Men & \multicolumn{3}{|c|}{} \\
\hline Have restrictions of life activities & 17.5 & 10.5 & 20.4 & 20.6 & 30.7 \\
\hline No restrictions & 0.0 & 0.9 & 0.7 & 1.2 & 0.0 \\
\hline
\end{tabular}

Source: calculated as per data obtained via Russian Social Survey with IBM SPSS Statistic software (ver.22.0).

comes down to women without any restrictions, we should note that the highest share of negative health assessments was detected among those aged 40-49. This might be due to women in this age group paying special attention to feeling bad and having malaise when they assessed their health; these disorders didn't result in any restrictions but created certain discomfort (Table 6).

Since we have managed to reveal a certain correlation between self-assessment of health and existing restricted life activities, let us now consider whether we can use these parameters for estimating latent disability among population. $2 \%$ (45 people) among respondents aged 60-69 who took part in the examined survey were registered as disabled; another $7 \%$ (138 people) had restricted life activities and assessed their health as poor or very poor. Disability among women, apart from restricted life activities, was more often accompanied with negative assessment of health $(72.7 \%)$ whereas a considerable share of men $(26.1 \%)$ stated they didn't have any restrictions of life activities and assessed their health quite positively. It is probably due to these respondents having failed to adapt to their condition. Negative self-assessment of health is not detected among disabled people without any restrictions in life activities whereas it is still possible to assess one's health positively even if there are restricted life activities. $5.4 \%$ of men who were not registered as disabled simultaneously stated that they had restrictions in life activities and gave negative assessments of their health. As for women, a share of those who were not disabled but still had restricted life activities amounted to $8.4 \%$ (Table 7).

We calculated Cramer's V-coefficients for the examined variables to determine to what extent officially registered disability was 
Table 7

Combination table: "negative self-assessment of health and restricted life activities" and "disability' variables (in \% of the overall number of respondents)

\begin{tabular}{|l|c|c|c|c|}
\hline \multicolumn{1}{|c|}{ Health parameters } & \multicolumn{2}{c|}{$\begin{array}{c}\text { Respondents not officially } \\
\text { registered as "disabled" }\end{array}$} & \multicolumn{2}{c|}{$\begin{array}{c}\text { Respondents officially } \\
\text { registered as disabled }\end{array}$} \\
\hline Sex & men & women & men & women \\
\hline $\begin{array}{l}\text { Negative self-assessment of health and restricted life ac- } \\
\text { tivities }\end{array}$ & 5.4 & 8.4 & 43.5 & 72.7 \\
\hline $\begin{array}{l}\text { Positive self-assessment of health and restricted life ac- } \\
\text { tivities }\end{array}$ & 22.5 & 27.2 & 30.4 & 27.3 \\
\hline $\begin{array}{l}\text { Negative self-assessment of health and absence of re- } \\
\text { stricted life activities }\end{array}$ & 0.4 & 1.3 & 0.0 & 0.0 \\
\hline $\begin{array}{l}\text { Positive self-assessment of health and absence of re- } \\
\text { stricted life activities }\end{array}$ & 71.7 & 63.1 & 26.1 & 0.0 \\
\hline
\end{tabular}

N o t e : $100 \%$ as per columns

Source: calculated as per data obtained via Russian Social Survey with IBM SPSS Statistic software (ver.22.0).

related to a combination of negative health assessment and restricted life activities in different sex and age groups. According to the obtained results, the strongest correlations between "disability" and "negative selfassessment of health and restricted life activities" variables were detected for women aged 20-29 and 30-39; the weakest ones, for men and women aged 60-69. That is, if young women have restrictions in life activities and assess their health negatively, it is quite probable that they are simultaneously disabled. Low values of the calculated coefficient in older age groups indicate there is greater probability that a number of disabled people is underestimated in these age groups in spite of poorer health (in comparison with younger age groups). This situation may be due to, on one hand, elderly people having weaker motivation to register officially as disabled after retirement; on the other hand, due to a share of negative assessments of health being naturally higher in older age groups regardless of disability. Calculated values of the coefficient indicate that a number of disabled people is more likely to be underestimated for men than for women, the only exception being an age group 50-59 (Table 8). A weak correlation between the examined variables for men may indicate that disability is not always combined with restricted life abilities and negative selfassessment of health among them. If we correlate this result with previously mentioned as- sumption about greater correlation between self-assessment of health and restricted life activities among men (in comparison with women), we can come to the following: men to a greater extent tend to take restricted life activities into account when assessing their health, but combined restrictions and poor health are less likely to indicate there is officially registered disability.

Let us analyze a number of respondents with a combination of "negative self-assessment of health" and "restricted life activities" who are not officially registered as disabled in the examined age and sex groups. The highest share of respondents with these two parameters was detected among women and men aged 60-69 (20.3 and 19.5\% accordingly). Bearing in mind that there is a weak correlation between disability and restricted life activities and negative self-assessment of health in these groups of respondents, we can assume that a number of disabled people is the most likely to be underestimated in them. $3 \%$ among men aged 20-29 had restricted life activities and assessed their health as poor or very poor. Bearing in mind, that the examined parameters are relatively weakly correlated with officially registered disability, we can assume that these $3 \%$ men can also make a contribution into latent disability. The same is true for $4.8 \%$ respondents with such parameters among men aged 40-49. As it has already been shown, men aged 30-39 tend to have the least apparent 
Cramer's V coefficient values "negative self-assessment of health and restricted life activities" and "disability" variables in different sex and age groups

\begin{tabular}{|l|c|c|c|c|c|}
\hline \multirow{2}{*}{ Sex } & \multicolumn{5}{|c|}{ Age groups } \\
\cline { 2 - 6 } & $20-29$ & $30-39$ & $40-49$ & $50-59$ & $60-69$ \\
\hline Men & 0.263 & 0.309 & 0.228 & 0.368 & 0.119 \\
\hline Women & 0.496 & 0.493 & 0.401 & 0.338 & 0.198 \\
\hline
\end{tabular}

Source: calculated as per data obtained via Russian Social Survey with IBM SPSS Statistic software (ver.22.0).

correlation between self-assessment of health and restricted life activities. At the same time, a combination of these parameters is even more weakly correlated with officially registered disability. It indicates that men from this age group are to the smallest extent prone to try and register themselves as disabled officially even when they have restrictions in life activities; it also means that these men tend to probably overestimate their health. This age group among men is the most difficult for revealing scales of latent disability via social survey techniques. The strongest correlation between officially registered disability and restricted life activities and negative assessment of health is detected among men aged 50-59 (in comparison with other age groups among men). There is also an average correlation between negative self-assessment of health and existing restricted life activities detected for this group of respondents. $5.9 \%$ men in this age group had the above mentioned parameters but were not officially registered as disabled. These respondents can be considered people who in future may apply for being officially registered as disabled.

A share of women with restricted life activities and negative self-assessments of health varied from $1.6 \%$ among those aged $20-29$ to
$8.5 \%$ among those aged $50-59$. We have already shown that a correlation between selfassessment of health and existing restricted life activities was weaker among women aged 20-29 and 40-49 and a correlation between these parameters and officially registered disability was stronger in these age groups than in older ones. At the same time, women who don't have any restrictions of their life activities still tend to underestimate their health. These facts indicate that women from the above mentioned age groups are less likely to be latent disabled since they are rather alert regarding their health and readily apply for being officially registered as disabled in case it is necessary. As it has already been shown, there is an average correlation between restricted life activities and negative self-assessments of health detected among women aged 50-59. A correlation between selfassessments of health and existing restricted life activities is just a bit weaker among women from this age group than among those aged 60-69. These facts indicate that when women retire, they have weaker motivation to be officially registered as disabled even if there are restricted life activities. Therefore, $8.5 \%$ female respondents from this age group can also be conditionally considered to be latent disabled (Table 9).

Table 9

Number of respondents with restricted life activities and negative self-assessment of health in different age and sex groups

\begin{tabular}{|l|c|c|c|c|c|}
\hline \multirow{2}{*}{ Sex } & \multicolumn{5}{|c|}{ Age groups } \\
\cline { 2 - 6 } & $20-29$ & $30-39$ & $40-49$ & $50-59$ & $60-69$ \\
\hline Men, people & 7 & 4 & 9 & 8 & 22 \\
\hline \% of the overall number of people in an age group & 3.1 & 1.5 & 4.8 & 5.9 & 19.5 \\
\hline Women, people & 3 & 6 & 10 & 21 & 48 \\
\hline$\%$ of the overall number of people in an age group & 1.6 & 3 & 5.5 & 8.5 & 20.3 \\
\hline
\end{tabular}

Source: calculated as per data obtained via Russian Social Survey with IBM SPSS Statistic software (ver.22.0). 
Conclusion. In our research we tested an assumption that people who were not officially registered as disabled still had a risk that they might have to do so in future in case they already had restricted life activities and assessed their health as poor or very poor. In its turn, a considerable share of such people among overall population may indicate that they either don't want to apply for being officially registered as disabled or they face objective difficulties in trying to get this official "disabled" status.

This research allows concluding that a combination of such criteria as "negative selfassessment of health" and "existing restricted life activities" can be considered risk indicators showing a risk of latent disability among adult population. It has been shown that a combination of these parameters to a greater extent correlated with official disability among men aged 50-59 and women aged 20-29, 30-39 and 40-49. Respondents from these groups who have restricted life activities and assess their health as poor or very poor are more likely to be officially registered as disabled in future. The situation is a bit more difficult when it comes down to men and women aged 60-69: restricted life activities combined with negative self-assessment of health are more frequent in these groups but these parameters to a smaller extent correlate with official disability than in other age groups. These facts may indicate that elderly people either don't want to apply for being officially registered as disabled or they face certain difficulties in doing so. Given that, elderly men and women are more likely to be latent disabled.
The least exact results in revealing latent disability via applying these indicators were obtained for men aged 30-39. There is a weak correlation between self-assessment of health and restricted life activities detected for this group of respondents, on one hand, and also a weak correlation between these parameters and officially registered disability, on the other hand.

To determine latent disability is a task with great practical significance since, on one hand, it allows revealing population groups with elevated risks of underestimated number of disabled people in them; on the other hand, it helps make timely managerial decisions regarding disability prevention and providing support for risk groups. Revealing latent disability also allows reducing a probability of mistakes in predicting expenditure on social support for population and public healthcare. Bearing in mind that the issues discussed in the present work are rather complicated, it is necessary to accomplish further examinations using data obtained via other representative social questionings (including regional ones); it will allow solving methodological issues when the examined criteria are used to estimate latent disability (including estimations performed as per different age and sex population groups).

Funding. The study is accomplished with the State Task for the Vologda Scientific Center of the RAS on the subject entitled "Demographic development of territories".

Conflict of interests. The authors declare there is no any conflict of interests.

\section{References}

1. Disability and health. World Health Organization. Available at: https://www.who.int/newsroom/fact-sheets/detail/disability-and-health (02.05.2020).

2. Vasin S.A. Legkoe bremya invalidnosti [Insignificant burden of disability]. Demoskop Weekly, 2007, no. 283-284. Available at: http://www.demoscope.ru/weekly/2007/0283/analit07.php (23.04.2020) (in Russian).

3. Brief Model Disability Survey. Implementation Guide. World Health Organization, 2018, 24 p.

4. Makarentseva A.O., Vasin S.A., Khasanova R.R. Kak otsenit' chislo invalidov v Rossii [How to estimate a number of disabled people in Russia]. Demoskop Weekly, 2016, no. 695-696. Available at: http://demoscope.ru/weekly/2016/0695/tema01.php (29.04.2020) (in Russian).

5. Kozyreva P.M., Smirnov A.I. Social well-being dynamics among the disabled: concerns and hopes. Sotsiologicheskie issledovaniya, 2019, no. 8, pp. 62-74 (in Russian). 